\title{
Risk management in a bulk coal export logistic chain: A stakeholder perspective
}

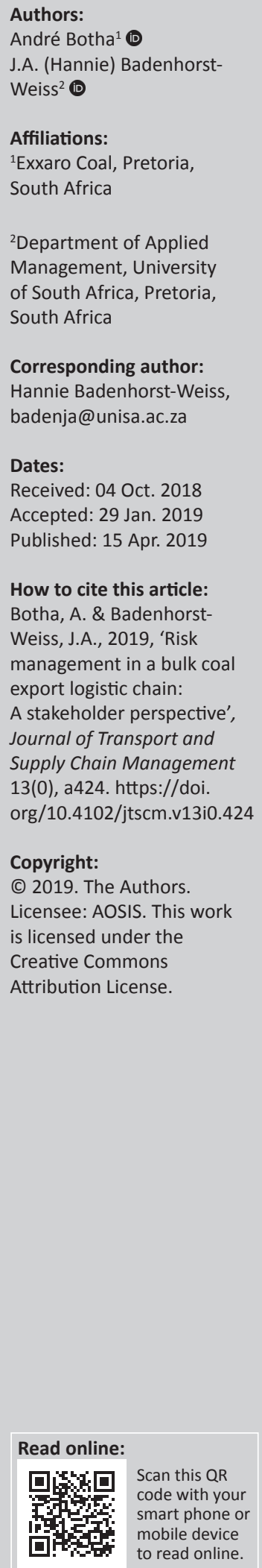

Background: In South Africa, the export of coal is a large contributor to the gross domestic product. Statistics indicate that the export of coal is stagnant or declining, which indicates a risk for coal as a foreign exchange earner. A study into the risks facing the bulk coal export logistics chain is therefore of great importance. Any risk to this logistics chain will directly affect its efficiency and contribution to foreign exchange. The nature of a logistics supply chain is such that risks to one stakeholder (partner or node) affect not only that stakeholder's own operations but also those of the other partners and the whole supply chain's efficiency and sustainability.

Objectives: The objective of the study was to identify and explore the risks and risk management practices in the bulk coal export logistics chain from a stakeholder theory perspective.

Methods: A qualitative research design was used, and in-depth, structured interviews were conducted with different stakeholders in the chain. A total of eight interviews were conducted, audio-recorded, transcribed and analysed by means of a thematic analysis.

Results: Many risks were identified in the bulk coal export logistics chain, and of these risks, it was found that the most important ones were infrastructure, the macro-economy and people-related risks. The findings revealed evidence of underlying tensions between different stakeholders with regard to investment to mitigate infrastructure risks. The findings suggest that there is a lack of communication and an aligned vision among the stakeholders in the logistics chain and that they strategise for their risks separately.

Conclusion: Close cooperation on a high level between the stakeholders in the logistics chain is needed to strategise for risk mitigation in an integrated, holistic manner.

Keywords: logistics; risk management; bulk coal export logistics chain; stakeholder perspective; risk management; risk mitigation; risk score; infrastructure; qualitative research; thematic analysis; triangulation; developing countries.

\section{Introduction}

We live in a risk-prone world. The risk of natural disaster has increased over the past decade (Bereriche \& Ait-Kadi 2015:31). There is also a higher risk from man-made disasters, such as terrorism, which currently occurs very frequently (Sodhi, Son \& Tang 2012:72). Companies that do not manage their risks are exposed to the risk of increased losses in the event of disruptions (Christopher et al. 2011:68). A series of disasters over the last decade, such as Hurricane Katrina in the United States, Hurricanes Irma and Maria in the Caribbean (in 2017), Hurricane Frances in North and South Carolina (in 2018), the terrorist attacks of 9/11, the tsunami in 2011 and the 2016 earthquake in Japan disrupting the logistics and operations of Toyota - and many more - demonstrated the vulnerability of logistic chains (Stecke \& Kumar 2009:200; Toyota 2011, 2016).

The aim of this study was to explore the risks and the management of risks in the bulk coal export logistics chain from a stakeholder theory perspective. According to the stakeholder theory, the activities of companies in a supply chain affect both internal and external parties (Touboulic \& Walker 2015). Risk management can be understood as the responsibility of a company to meet the expectations of its various stakeholders. Companies can ensure their long-term survival by taking into account the broad network of actors in their (risk) strategy. Companies are embedded in networks of stakeholders and activities and decisions are often shaped by pressures from external stakeholders. Supply chain stakeholders (customers, suppliers, etc.), their influence and their role in risk should be identified (Touboulic \& Walker 2015). 


\section{Background}

This study involved mainly logistics and the movement of coal as mining commodity for the export market and the risks attached to it.

Logistics has an influence on the economic development of a country and has a direct effect on the economy by facilitating and making trade possible (Fawcett, Waller \& Bowersox 2011:115-116). Logistics is increasingly relevant to the rapid economic growth of emerging economies (Hirschinger et al. 2015:74) and a direct correlation can be seen between the logistics capability of a country and the volume of trade. Developing countries with better logistic chains will fare better in the global market and, hence, develop their economies (Hausman, Lee \& Subramanian 2013:237).

Many developing countries, such as Brazil, Peru, Chilli and South Africa, depend on the export of bulk minerals as an earner of foreign revenue to maintain and govern the country's economy (Roe \& Haglund 2012:3). The South African economy was built on the back of mining. Mining was the second most influential industry in 1980, with its $21 \%$ contribution to the gross domestic product (GDP). In 2012, the mining sector cumulatively contributed $18 \%$ (R330 billion) to the GDP (Bandaly et al. 2012:249; Smit 2013), and in 2016, the industry contributed $8 \%$ (STATS SA 2017), indicating that the country has developed its economy and is depending less on the primary sector. Nevertheless, it remains an important sector, particularly with regard to employment. According to the Minerals Council South Africa (previously called the Chamber of Mines of South Africa), the coal industry employed more than 77000 workers in 2016, indirectly creating and sustaining 170000 employment opportunities outside the coal industry (CMSA 2018). The reason for the decrease in mining activity is gold production, which has declined over the decades (STATS SA 2017). Statistics from the South African Chamber of Mines indicate that coal is by far the most important mining commodity, followed by gold and then platinum. In 2012, the total sales revenue from coal was R96.1bn, with R52.2bn of this revenue derived from the export of coal (Ryan 2014). Coal is exported at a price of more or less R740.00 per ton and locally sold for R337.00 per ton (2016) (Seccombe 2018). South Africa exported about $30 \%$ of its total domestic coal production (96 million ton) in 2016. It is clear that export sales are declining, for South Africa has traditionally exported between $40 \%$ and $45 \%$ of its total coal sales. Total exports were valued at R50.5bn in 2016 (CMSA 2018), in comparison with the total coal export sales of R52.2bn in 2012 (Ryan 2014).It is clear that coal is an important foreign exchange earner but that there are signs of stagnation or decline. According to the Chamber of Mines Coal Leadership Forum, transport and storage costs account for more than $50 \%$ of the total industry costs (excluding value add) (CMSA 2018). Efficiency in the logistics chain is therefore of the utmost importance for the exporting of coal. It is crucial for the country to sustain this bulk coal export link. Therefore, a study of the risks that can cause inefficiency and disruptions and further decline in coal exports is necessary.

The export of coal is not possible without proper logistics infrastructure. Coal for export is mainly transported by rail from the mines in Mpumalanga to Richards Bay Coal Terminal (RBCT), where the coal is loaded on vessels and shipped to its destination. It is obvious that if a man-made or natural disaster were to occur anywhere in the bulk coal export logistics chain to the harbour, it will have a devastating effect on sustainability for stakeholders and the economy of South Africa, and particularly the trade balance.

Although risk cannot be avoided, the effect needs to be understood and managed to minimise it (Latif et al. 2013:20). It is necessary to ensure the minimum effect through adequate risk mitigation to protect the sustainability of organisations. Organisations which are part of a bulk export logistics chain should have a focussed, implemented and operational risk management strategy (Tomlin \& Wang 2011:80).

The bulk coal export logistics chain consists of 21 stakeholders, including 19 coal exporting parties (CEPs) (mining companies), Transnet Freight Rail (TFR) and RBCT. Based on the companies' financial statements available in the public domain, it is evident that risk management is an important focus area for them.

The aim of this qualitative study was to explore the risks and risk management practices of the stakeholders in the bulk coal export logistics chain. The study was conducted by means of in-depth interviews.

\section{Literature review}

\section{Risk}

Risk can be defined in terms of three dimensions: uncertainty, probability and effect (or consequence) (Breakwell 2014:3).

All human endeavours and operations carry some risk and uncertainty (Olson \& Dash Wu 2010:694). As the term implies, uncertainty is something that is doubtful or unknown. The close connection between risk and uncertainty is illustrated by the International Organisation for Standardisation's (ISO) definition of risk: 'Risk is the effect of uncertainty on objectives'. In whatever way people use the term 'risk', there is always a common element, namely, the fact that there is uncertainty about a future outcome (Tranchard 2018). There is a distinction between uncertainty related to a known event and uncertainty related to an unknown event; the former is called risk and the latter is called pure uncertainty (Kumar \& Gregory 2013:275). The degree of uncertainty surrounding the event determines the level of risk. The more uncertain the decision maker is of whether the event will take place and what the outcome will be, the greater the possible deviation of the actual from the expected result. Simchi-Levy, Kaminsky and 
Simchi-Levy (2009:316) prefer to use 'known-unknown' and 'unknown-unknown' risks. According to them, certain sources of risk such as supplier performance, forecasting accuracy and operational problems are risks that can be quantified and hence are referred to as known-unknown risks, which are more controllable risks. On the other side of the spectrum is the unknown-unknown risk such as natural disasters that are difficult to control. Between the two extremes are various types of risks that can be controlled to some extent by following certain strategies, such as hedging as a strategy to alleviate currency risks. Because of the effect of uncertainty in risk, risk cannot be eradicated but only mitigated with riskreducing actions, referred to as risk management strategies (Lockamy 2014:757).

McLaughlin (2015:39) defines probability as a frequency of events, and consequence as the effect of the events. These two dimensions (frequency and consequence/effect) of risk require intervention (mitigation), as studies show that frequency and consequences in the modern times are elevated (Son \& Orchard 2013:684). Probability is the chance that something will happen or that has a chance of happening (Merriam-Webster, n.d.). Data from history in conjunction with modelling are used to measure probability. Often these models involve various statistical measures that entail correlations (strength of association between two variables) and dependencies (the quality or state of being dependent, especially the quality or state of being influenced or determined by, or subject to another) (Merriam-Webster, n.d.). In conclusion, probability is the quantifying measure on which risk assessment can be based (McLaughlin 2015:40).

Uncertainty in terms of risk exerts a consequence or effect or impact on the object (Hopkin 2012:34). Elahi (2013:113) defines this consequence/effect/impact as a 'business outcome' that has an effect on the organisation.

Therefore, risk can be explained by the following formula of McLaughlin (2015:39):

\section{Risk (uncertainty) $=$ Probability $($ Change of} happening) $\times$ Consequence (effect/impact)

[Eqn 1]

This means that:

- Risk cannot be avoided because of 'uncertainty' and risk will always exist (Lockamy 2014:757).

- Risk can be quantified as a result of probability (the chance of happening) and the consequence/effect, and this consequence/effect can have a value attached to it (McLaughlin 2015:40).

\section{The risk management process}

Three important steps in the risk management process are risk identification, risk evaluation and risk mitigation and control (Botha et al. 2016:144-145).
The first step in the management of risk is to identify and assess the different risks, specifically in order to determine the supply chain management risk profile. The identification and assessing and categorisation of risks will be discussed in more detail in the next section - Supply chain (SCRM) and logistics risk management (LRM).

The second step - risk evaluation assesses the probability and consequence/impact/effect of the risks on the institution. This step includes considering aspects such as risk appetite, which is defined as the amount and type of risk that an organisation is prepared to pursue, retain or take' (IRM n.d.), and using a risk matrix to determine how likely a risk will occur and to what extent would such a risk impact on the sustainability of the institution. Figure 1 displays an impact (consequence) versus probability risk matrix, which assists in determining the risk scoring and risk profile of each risk identified.

In Figure 1, the probability that a risk will occur is evaluated with a 5-point scale. The probability or likelihood of a risk can be weighted in the following categories: $5=$ almost certain; 4 = very likely; 3 = likely / possible; 2 = unlikely; 1 = rare. On the impact (consequence/effect) part of the matrix, the severity of the impact is shown on a 5-point scale with 5 = extreme; 4 = high; 3 = medium; 2 = low; $1=$ negligible. In Figure 1, the $\mathrm{L}$ indicates a low likelihood/impact, $\mathrm{M}$ a medium likelihood/impact and $\mathrm{H}$ a high likelihood/impact. With this matrix, a score for each risk can be determined. For example, if the likelihood that a risk will occur is high (say 4) and the impact/severity of the risk is high (say 4), the risk score will be 16 , which makes it a very high-risk item, which needs high-level management attention and action.

The third step in the risk management process consists of determining a risk response strategy or action plan to deal with or eliminate the risks, also known as risk mitigation and control. In managing risks, the following are the options to consider: risk avoidance, risk assumption, risk reduction, risk transfer (Hugo \& Badenhorst-Weiss 2011:103/4). Risk avoidance means drastic action is taken in order to eliminate the chance of loss. In practice, it means changing suppliers, using alternative materials, ceasing some operations that have been carried out in the past or selecting a business location where a certain peril is not present. The peril of flooding can, for example, be avoided by locating the inventory storage facilities of the organisation in an area where flooding is impossible. Risk assumption means that the consequences of the loss will be borne by the party exposed to the possibility of loss, which is often a deliberate risk management decision. Many risks are assumed because the consequences of the loss are not costly enough to justify other risk management measures. This applies typically to minor, infrequent losses. Risk elimination introduces standards, procedures and actions necessary to eliminate risk. Having a back-up facility at a distant location will, for example, eliminate the loss of data by fire. Risk reduction is aimed at reducing the likelihood of occurrence of loss. Because losses 


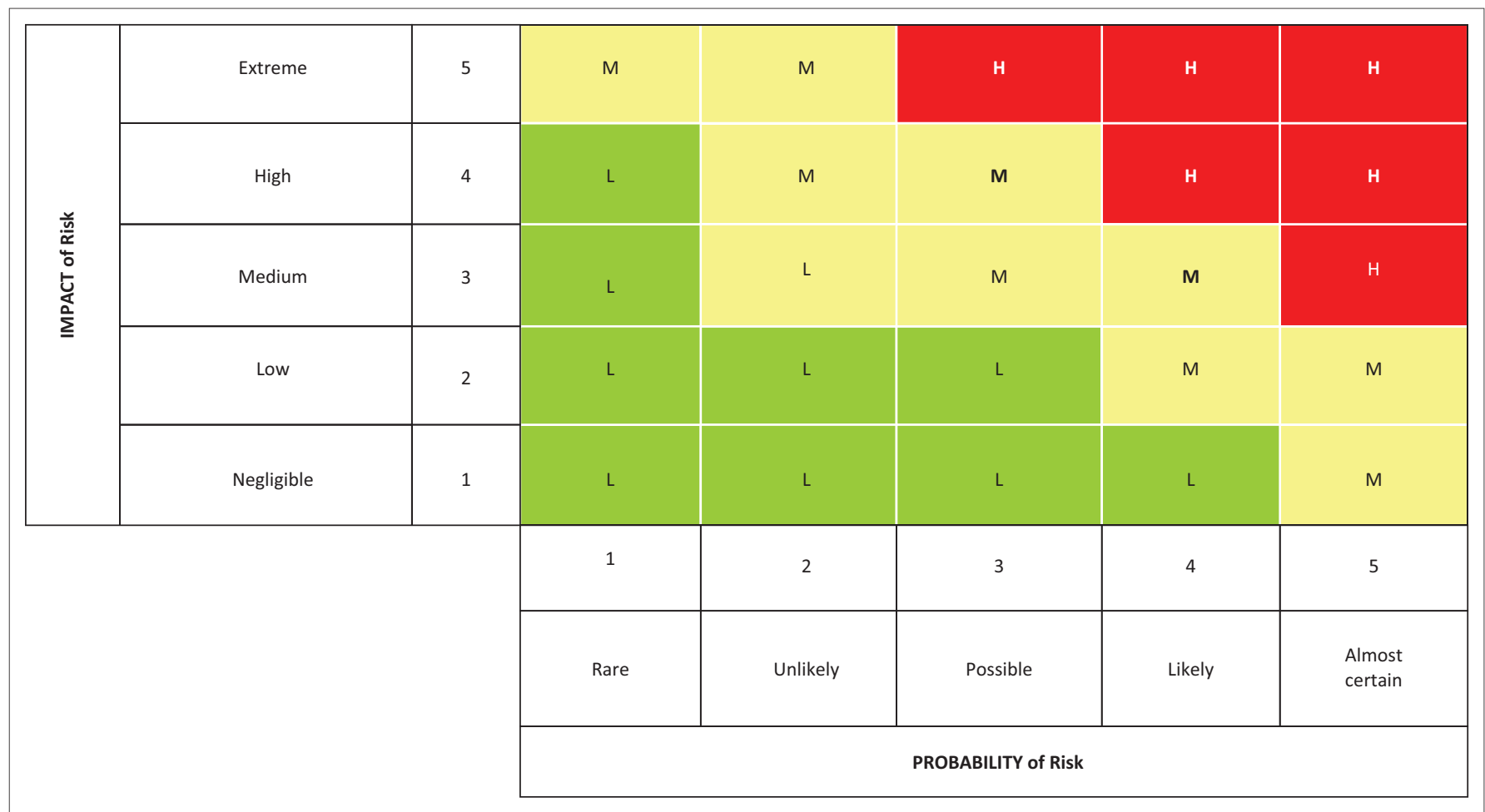

Source: Adapted from Intelex Library, nd. Risk Matrix Example, viewed 9 January 2019, from https://community.intelex.com/library/peer-resources/risk-matrix-example L, low likelihood/impact; $M$, medium likelihood/impact; $H$, high likelihood/impact.

FIGURE 1: Risk rating matrix (Impact-probability matrix).

occur despite the best efforts of the management, risk reduction is also aimed at reducing the impact of the loss. An example of a loss reduction device is a firewall. Risk transfer means that the risks are transferred to another party, such as taking out insurance, or lease equipment rather than buying it. Because risk is unavoidable, the effect thereof requires understanding and insightful management. Therefore, in modern strategic business planning, a risk management plan is essential (Latif et al. 2013:20). The purpose of risk management is to improve the future and not to explain the past (Borge 2001:6). Collaboration in supply chains does not only offer opportunities but also creates more risk (Breuer et al. 2013:332). Consequently, risk and risk management in supply chains has become a growing field of research and practice (Bandaly et al. 2012:254).

\section{Supply chain risk management and logistics risk management}

Supply chain risk management can be defined as ' $(t)$ he practice of managing the risk of any factor or event that can materially disrupt a supply chain, either within a single company or spread across multiple companies' (Kessinger \& Macmorrow 2012:517). The ultimate purpose of SCRM is to enable cost avoidance, to continue customer service levels and to maintain market position (Kern et al. 2012:517). Logistics is the work required to move and position the product throughout the supply chain. Logistics is primarily the conduit of product and service flow within a supply chain (Bowersox et al. 2013:4). The objective of logistics is thus to have (1) the right material, (2) in the right quantity, (3) at the right time, (4) at the right place and then (5) within the right cost (Fuchs \& Wohinz 2009:234). Logistics risk can be regarded as any unexpected, unwanted event that causes the inventory not to be at the right place, at the right time, in the right quantity or quality, at the right cost (Fuchs \& Wohinz 2009:234).

Logistics risk management invariably has the same risk sources as risk management and SCRM, owing to the fact that the scope of logistics management crosses various functional management areas and stakeholders across the supply chain (Peck 2006:139-140). Various authors have identified and classified risk management in the supply chain and logistics chain in different ways. However, there is a large extent of overlap in the sources and classification (Sodhi et al. 2012:11).

Wagner and Bode (2008:310) identified five risk sources owing to disruptions in the supply chain. They are: (1) demand-side, (2) supply-side, (3) regulatory, legal and bureaucratic, (4) infrastructure and (5) catastrophic sources. These risk sources can further be grouped into sources internal to the supply chain, or external to the supply chain. Fuchs and Wohinz (2009) similarly categorised LRM into logistics risk sources, risk releasers and risk amplifiers (strategic product importance). Logistic risk sources consist of an internal source (material flow system and information flow system) and an external source (supplier, customer and environment). In addition to the LRM sources, Fuchs and Wohinz (2009) introduced the following logistics risk releasers that prevail with any logistic risk occurrence: human failure, technical failure, organisational failure and 
force majeure. These classifications or categorisations highlight the different dimensions of sources of risks in supply and logistics chains.

\section{Defining the bulk coal export logistics chain}

To understand the areas of risk in the bulk coal export logistics chain, the scope of the logistics chain should be defined. The scope of logistics includes (1) the identification of the nodes and (2) the four flows: service/product flow, information flow, cash flow and market accommodation flow (Bowersox et al. 2013:357). This article will focus on the first two flows, which are most important for this type of logistics chain and risk and risk management.

The nodes of the bulk coal export chain are the CEPs (mining companies), TFR and RBCT. Figure 2 illustrates the nodes in the bulk coal export logistics chain (Figure 2).

The CEPs are producers who produce coal for export. Over $80 \%$ of South African coal is produced by five leading international natural resources (mining) companies, namely, BHP Billiton, Anglo Coal, Xstrata, Exxaro and Sasol. The rest of the coal is produced by smaller companies, mainly owned by black empowerment groups that are also affiliated to the main role-players in the industry (Mathu \& Chinomona 2013:347).

Transnet Freight Rail, a business unit of Transnet (a stateowned enterprise), is one of the most important logistics companies in the South African coal industry (Mathu \& Chinomona 2013:355). As such, TFR is the logistical rail transport service provider that is responsible for receiving the coal and transporting it to RBCT. Richards Bay Coal Terminal, a bulk coal terminal, receives, stacks and stores the coal until the customer's nominated vessel arrives in port to receive the coal, sold free-on-board. Richards Bay Coal Terminal represents the customer's nominated destination (Benyahia 2012:95).

The main flows (as previously indicated) in a bulk coal export chain are (1) service/product flow and (2) information flow.

\section{Service or product flow}

The product or service flow comprises activities that ensure the movement or storage of the coal. In the logistics chain, the nodes can be divided into two categories: (1) a node that provides the product and requires product flow or service

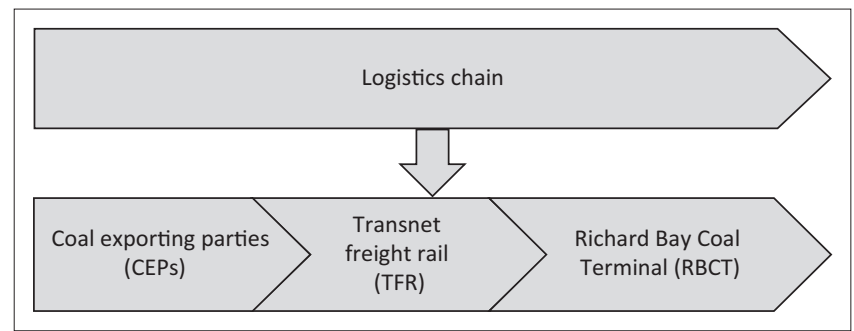

FIGURE 2: The bulk coal export logistic chain. (the CEPs) and (2) a node that is responsible for and has the primary function of executing product flow or service (TFR and RBCT). Figure 3 depicts the activities involved in the product flow.

\section{Information flow}

The information flow supports the product/service flow and acts as an initiator and controller of the movement of the material. Accuracy of the information flow is extremely important, as this governs the inventory (bulk coal) and the movement of inventory (Bowersox et al. 2013:34). Figure 4 depicts the information flow in the bulk coal export logistics chain.

From Figures 3 and 4, it is clear that the bulk coal export chain involves a few critical nodes and many actions or activities and resources. It is obvious that at each node and with each activity there is a risk that can cause disruption in the logistics chain. History has shown that some disruptions have in fact occurred in the bulk coal export logistics chain in the last few years. Table 1 contains a list of some of the logistics risk sources.

\section{Research method and design}

The objective of the study was to identify and explore the risks and risk management practices in the bulk coal export logistics chain from a stakeholder theory perspective. Insight into risk and risk management will not only have advantages for individual stakeholders but also for the whole logistics chain, and eventually the South African economy. This research followed a qualitative approach with in-depth interviews to understand and develop a richer and deeper understanding (Gammelgaard \& Flint 2012).

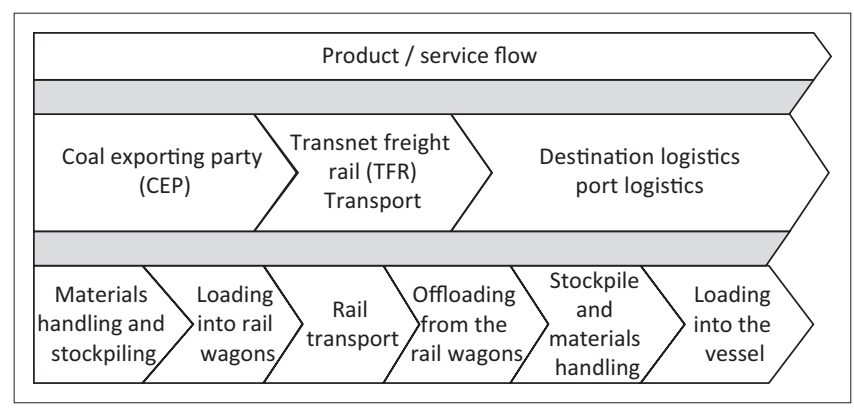

FIGURE 3: The product flow activities at the different stages in the bulk coa export logistic chain.

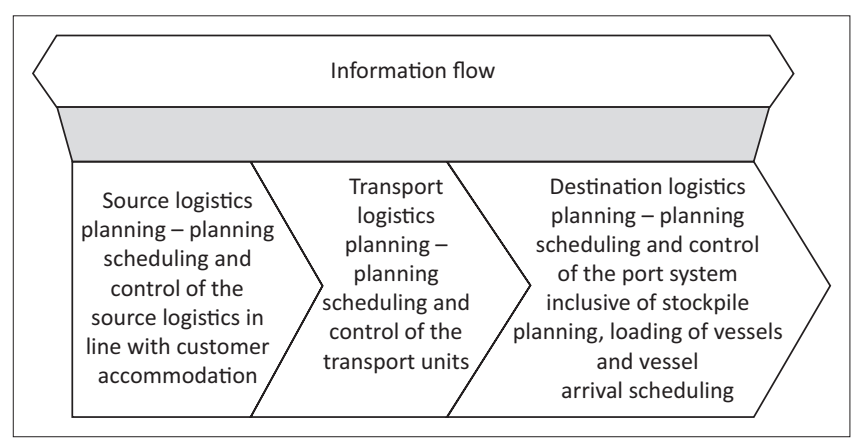

FIGURE 4: Information flow in the bulk coal export supply chain. 
TABLE 1: Risk sources.

\begin{tabular}{|c|c|c|c|c|}
\hline Service/product flow & Information flow & Source logistics & Destination logistics & Environment \\
\hline $\begin{array}{l}\text { Coal spillage on track must be } \\
\text { cleared prior to rail } \\
\text { commencement (Boland \& } \\
\text { Savelsbergh 2012:287) }\end{array}$ & $\begin{array}{l}\text { Lack of collaboration between } \\
\text { role-players in the supply chain } \\
\text { (Boland \& Savelsbergh 2012:278) }\end{array}$ & $\begin{array}{l}\text { Production delays at the source } \\
\text { (Ernst et al. 2008:178) }\end{array}$ & $\begin{array}{l}\text { Technological accidents (Rose \& } \\
\text { Wei 2013:212) }\end{array}$ & $\begin{array}{l}\text { Increased demand and fluctuations } \\
\text { in demand (Boland \& Savelsbergh } \\
\text { 2012:278) }\end{array}$ \\
\hline $\begin{array}{l}\text { Theft of signal cables results in } \\
\text { service disruptions (Transnet } \\
\text { 2013:56) }\end{array}$ & - & $\begin{array}{l}\text { Loading disruptions at the source, } \\
\text { inventory depletion, } \\
\text { machine equipment failure } \\
\text { (Sivhaga 2012:18) }\end{array}$ & $\begin{array}{l}\text { Electrical outages, } \\
\text { equipment breakdown } \\
\text { (Gurning \& Cahoon 2009) }\end{array}$ & $\begin{array}{l}\text { Political events (Gurning \& } \\
\text { Cahoon 2009) }\end{array}$ \\
\hline - & - & - & $\begin{array}{l}\text { Recovery of rail-related } \\
\text { disruptions manifest later at the } \\
\text { port in terms of demand } \\
\text { scheduling and queuing } \\
\text { disruptions (Boland \& } \\
\text { Savelsbergh 2012:285) }\end{array}$ & - \\
\hline
\end{tabular}

\section{Population and sample}

The population for this study was the Channel Oversight Team (COT) of the bulk coal export logistics chain. The COT was formed among the stakeholders in the bulk coal export logistics chain to cooperatively seek to ensure international competitiveness of the coal logistics chain and to focus on extracting efficiency and productivity opportunities in the channel (Mining Weekly 2018). The COT includes senior representatives of the CEPs (or producers), TFR and RBCT a total of 21 stakeholders. For this study, in-depth interviews were conducted with representatives of the different stakeholders on the COT. Two interviews were conducted with two representatives from each of two different CEPs, two interviews with TFR and two with Richards Bay Coal Terminal (RBCT). Therefore, eight in-depth interviews were conducted.

The participants were selected by means of the purposive sampling method of expert sampling. The advantage of this sampling lies in the in-depth understanding of the phenomena and abundance of phenomena-specific information that could be obtained (Patton 2015:599). The sample of eight participants was selected based on the following inclusion criteria: (1) knowledge of risk and risk management; (2) more than 10 years' experience; (3) representative of all the nodes in the logistics chain; (4) on a senior management level; (5) representative of race and sex; and (6) from small and medium (SMEs) and large CEPs.

\section{Research method}

The study started with a comprehensive literature study which included textbooks, journal articles, dissertations, theses and sector/industry magazines on the topics of risk and risk management in organisations, logistics and supply chains. The literature study was conducted to assist in the development of a research tool, an interview guide, for the primary data collection through semi-structured interviews.

The interview guide was used during the interviews to ensure that the relevant data were obtained from each participant. An audio recorder was used to capture the full detail of the interviews and the recordings were transcribed verbatim by a professional transcriber to increase the trustworthiness of the data (Elo et al. 2014:4).

\section{Analysis of data}

A thematic content analysis of the transcribed interviews with participants was conducted. Thematic analysis is defined by Smith and Firth (2011:57) as '... an interpretive process, whereby data are systematically searched to identify patterns within the data to provide an illuminating description of the phenomenon'. The process results in the development of meaningful themes without explicitly generating theory. Thematic analysis can provide rich and insightful understandings of complex phenomena. Through thematic analysis, themes, categories and codes are developed (Patton 2015:1178). The thematic data analysis for this study was done by following the six steps as suggested by Vaismoradi, Turunen and Bondas (2013:402). The steps are: familiarisation with the data, generating initial codes, searching for themes, reviewing themes, defining and naming themes, and producing the report.

\section{Trustworthiness}

Qualitative research cannot be evaluated against criteria suitable to quantitative research in terms of reliability and validity. Trustworthiness in qualitative research is normally associated with credibility, dependability, transferability and confirmability (Eriksson \& Kovalainen 2008:307). Dependability (in place of reliability) means that should the research be replicated, similar results would be achieved. In this study, dependability was established through the use of triangulation. Triangulation refers to 'overlapping methods', that is, the collection of data from different sources (and methods) in order to obtain more wide-ranging or holistic findings (Shenton 2004:71). In this study, the thematic content analyses of the interviews were triangulated with a content analysis (inductive and deductive) of documents of the participants' company risk management policies, procedures and risk registers. By triangulating the two sets of data, the researcher could obtain a complete overview of the phenomenon (Merriam 2015:216), thus ensuring confirmability (objectivity). Through this triangulation, the researcher also increased the validity (transferability) of the study (Sousa 2014:212). (The main purpose of the inductive and deductive content analysis of the company documents was for triangulation and owing to page restrictions, the process of these analyses will not be discussed in this article.) 
According to Shenton (2004:64), credibility in qualitative data refers to the internal validity of the data. Credibility of the interview questions was sought by involving an independent qualitative research expert who had no knowledge of the subject matter under investigation (Hallberg 2010:5387). The qualitative research expert reduced the initial list of nine questions to four appropriate, focussed interview questions, to answer the research question (Creswell 2013a:160). In addition, the audio recording of the first interview was sent to a qualitative research expert to review and provide feedback and quality approval (Creswell 2013b:274).

Transferability refers to external validity or generalisability, meaning the degree to which the findings of a study can be generalised to any other situations (Saldaña 2011:112). Transferability was achieved through the audio recording and transcription of the interviews. Confirmability refers to the objectivity of the research, most commonly determined through the audit trail kept by the researcher. For this study, the physical audit trail was kept in the form of audio recordings, transcriptions, the thematic data analysis of interview documents and the two-way content analysis of the company documents. The intellectual audit trail is established through the presentation of this article.

\section{Ethical considerations}

The researchers complied with the requirements of ethical research regarding consent, voluntary participation, informed consent, anonymity and confidentiality.

\section{Findings and discussion}

The eight participants all reflected a broad-based knowledge of risk management and the risks in their environment. The data from the interviews ranged from strategic risk management inputs to tactical and functional risk management inputs. The data gathered from the participants on certain themes did not differ significantly from participant to participant, but it was found that the participants from the service industries (TFR and RBCT) were more concise in identifying the risks, mitigating actions and proposed solutions than the participants representing the CEPs.

Table 2 summarises the thematic data analysis of the interviews in the form of a thematic map, structured in five themes, categories and codes, which are discussed in more detail in the sections that follow.

In the discussion of the thematic map below, some literature, direct quotes of the different participants (the interviewees are indicated as P1 to P8) and triangulation aspects are integrated - an acceptable practice in qualitative studies (Creswell 2009:81).

\section{Theme one - Infrastructure risk}

When considering the main activities in the bulk coal export chain indicated in Figure 3 (materials handling,
TABLE 2: Thematic map (themes, categories and codes).

\begin{tabular}{|c|c|c|}
\hline Theme & Category & Code \\
\hline \multirow[t]{5}{*}{$\begin{array}{l}\text { Theme one } \\
\text { Infrastructure }\end{array}$} & $\begin{array}{l}\text { Infrastructure investment } \\
\text { - Growth }\end{array}$ & $\begin{array}{l}\text { capital, infrastructure, } \\
\text { growth, investment }\end{array}$ \\
\hline & $\begin{array}{l}\text { Infrastructure investment } \\
\text { - Maintenance }\end{array}$ & $\begin{array}{l}\text { capital, infrastructure, } \\
\text { maintenance }\end{array}$ \\
\hline & Infrastructure - Ageing & infrastructure, ageing \\
\hline & Technology & technology \\
\hline & Overvaal tunnel & tunnel \\
\hline $\begin{array}{l}\text { Theme two } \\
\text { Macro-economy }\end{array}$ & $\begin{array}{l}\text { Macro-economy of coal } \\
\text { commodity }\end{array}$ & $\begin{array}{l}\text { economy, commodity, } \\
\text { market, price, future of coal }\end{array}$ \\
\hline $\begin{array}{l}\text { Theme three } \\
\text { Uncontrollable events of } \\
\text { nature }\end{array}$ & Nature & weather, water \\
\hline \multirow{4}{*}{$\begin{array}{l}\text { Theme four } \\
\text { Disruptions and risk that } \\
\text { occur in operations and } \\
\text { management }\end{array}$} & $\begin{array}{l}\text { Aligned vision among } \\
\text { stakeholders in chain }\end{array}$ & alignment \\
\hline & Communication & $\begin{array}{l}\text { communication, } \\
\text { information, transparency, } \\
\text { sharing }\end{array}$ \\
\hline & Electricity supply & Eskom power \\
\hline & Operational management & Operations, equipment \\
\hline \multirow[t]{2}{*}{$\begin{array}{l}\text { Theme five } \\
\text { People skills, labour and } \\
\text { social impact }\end{array}$} & People skills & $\begin{array}{l}\text { skill/s, knowledge, } \\
\text { expertise, people, } \\
\text { succession, transfer, old, } \\
\text { groom }\end{array}$ \\
\hline & Labour and social impact & $\begin{array}{l}\text { community, political, labour, } \\
\text { strikes }\end{array}$ \\
\hline
\end{tabular}

loading, rail transport, off-loading, stockpiling), it is clear that all of these activities require infrastructure. It is therefore obvious that infrastructure risk would be the predominant theme to emerge from all eight interviews. Infrastructure risk conforms to the source risk in the supply-chain risk categories (Wagner \& Bode 2008:310). The basics of infrastructure of the different stakeholders in the chain will be outlined below.

At the CEPs (coal production), infrastructure consists of the mines (excavation), infrastructure to make safe mining possible, systems and equipment such as conveyor-belt-orientated equipment, bucket scoops for reclaiming, front-end loaders and precision unit-train loading systems (PUTLS) (Sivhaga 2012:4).

Transnet Freight transports the bulk coal by rail over a distance of up to $580 \mathrm{~km}$. Rail transport consists of a system of rolling stock (locomotives, rail wagons), infrastructure (rail tracks, signalling systems, electric overhead cables) and operational systems (IT scheduling systems for planning, plan execution, train drivers and operational management personnel) (Luger 2008:219).

The activities at RBCT are receiving coal, storage and the handling of coal (Yan-liang 2013:3716). The infrastructure therefore consists mainly of bulk-handling systems that make the following activities possible: entrance activity (unloading of the rail wagons), the stockyard system (stockpile and materials handling) and an exit system (loading into a bulk vessel) (Christopher \& Lee 2004:376).

The theme 'Infrastructure risks' include five categories, namely, growth, maintenance, ageing, technology and the Overvaal tunnel, and are discussed below. 


\section{Growth}

The movement of bulk coal for the export market is totally dependent on logistics infrastructure. There is a direct correlation between the logistics capability (infrastructure) and economic growth in a country (Hirschinger et al. 2015:74). However, there are internal and external risks that can prevent growth in infrastructure. For example, investment is needed for growth. Participants mentioned a lack of investment in infrastructure at different stakeholders, and particularly in rail infrastructure in the coal link. One participant expressed the following views of infrastructure growth:

\begin{abstract}
'And I was unfortunate to pick up one of those cycles where there was no money to reinvest in the operation, which naturally then puts the whole system at risk, not only the operations, but the future of the whole system. And you know really, I think at the point in time we sit right now, there's a huge, huge problem that they're [other stakeholder]going to halt investment or not invest either in a new expansion, expansion in capital ... they've already made those kind of noises that it's not going to happen.' (Participant 1, white male, consultant, all nodes)
\end{abstract}

From this, one can almost feel the anxiousness of the participant and deduce that money to invest in infrastructure is tight, that investors are cautious to invest or that the priorities for investment are not this coal export line. Another participant's view is:

'So I do believe there is going to be a major crunch on capital which is a risk, which means then that if we could develop infrastructure, remember it is in dollars, it does not matter what anybody says, the company is doing the project work, the equipment that is being used etcetera, everything is actually dollar denominated. They won't be able to spend that capital, which will press back or push back the infrastructure programme of a lot of companies. (Participant 5, white female, large CEP, senior management)

This response also clearly indicates a lack of capital to invest in expensive infrastructure, particularly owing to the fact that the skills are not available in South Africa to develop infrastructure projects of this nature, and that service providers outside the country need to be contracted. Another participant feels that this coal line is not priority for further infrastructure investment anymore:

'I mean the future of South African coal lies in the Waterberg and obviously that line needs to be capitalised, but that's also back to who is going to invest in South Africa.' (Participant 3, white, male, small CEP, senior management)

Transnet is planning a heavy haul coal rail link between the Waterberg coalfield in Limpopo and Botswana (Luhanga 2017). The Transnet Long-Term Planning Framework (Transnet 2017a) clearly reflects other capital investment priorities, such as the Northern Mineral Belt in Limpopo, the Durban-Free State-Gauteng Logistics and Industrial Corridor, South-Eastern rail system development in the Eastern Cape and the Saldanha-Northern Cape Development Corridor. This means that TFR might prioritise their capital investment away from the Mpumalanga-Richards Bay bulk coal export line. This poses a serious risk for this logistics chain. Another participant's view of infrastructure growth risk is:

'So once again, if we're going to increase the traffic, in a pace, yes from a strategic point of view I know they want to move GFB [general freight business] traffic away from the coal line, but the risk for me in this is if our timing is not going to be spot on with regards to export traffic increasing and the timing that they want to move the GFB [general freight business] traffic away...because I know from a capital perspective they are moving our capital projects on, it is going to bite us and that is a concern for me as well.' (Participant 8 , white female, large service provider, senior management)

From this response, one can deduce that there is pressure on the CEPs to use the coal link optimally for exporting coal to justify investment in infrastructure on this line. The other parties (besides TFR) are worried about TFR's intentions with this coal link with regard to prioritising it for further investment and development. There is clearly tension in the logistics chain about investment in infrastructure. It is thus important for the whole logistics chain to consider risks that limit investment and the growth potential of individual parties and thus all the parties in the chain. A cooperative strategy in mitigation of this risk is important. CEPs need to invest in infrastructure and/or expand their export market to effectively use the capacity of the coal link. Transnet Freight Rail needs to invest in making the coal line more efficient and reliable for CEPs and RBCT, to ensure the capacity to handle a growth in export. It is of the utmost importance that TFR should be more open about their intentions with the coal line, to eradicate uncertainty among the other stakeholders.

\section{Maintenance and ageing infrastructure}

These two infrastructure risk categories are inextricably part of each other and are therefore discussed together.

Aggressive preventative maintenance programmes are necessary (Boland \& Savelsbergh 2012:286). Maintenance becomes important particularly owing to the age of the rail infrastructure. Some of the participants verbalised the risk as follows:

'Um I would hazard a guess, one of the biggest risks I see in, in the South African coal value chain is probably the rail infrastructure and I mean here the fixed lines and the overhead electrification and the long distances between mining operations and port um I think the number of bridges that we have along this value chain is, is probably one of the concerns to me specifically bearing in mind this coal value chain has been going since the early nineteen seventies.' (Participant 6, white male, service provider, senior management).

'The derailments, for example, are the symptoms of either the ageing of the infrastructure or poor maintenance on the infrastructure.' (Participant 4, black male, service provider, senior management)

'The biggest risk that I identify at the moment is ageing infrastructure.' (Participant 2, Indian male, large CEP, senior management)

Investment in maintenance is most important, particularly if no capital investment is made to replace or upgrade 
infrastructure. The data obtained from the participants indicate that all the stakeholders viewed investment in the form of maintenance of the infrastructure as a risk. Capital investment towards maintaining infrastructure is required. One participant summarised the maintenance risk as follows:

'Just to recap, ageing infrastructure, the actual railway line, and RBCT's equipment in terms of their stackers, re-claimers, tippers, these are huge, huge machineries that requires a huge amount of capital expenditure to replace.' (Participant 2, Indian male, large CEP, senior management)

From the data, it could be deduced that the CEPs viewed ageing logistics infrastructure in the logistics chain as a major risk, while the service delivery stakeholders felt more comfortable, for they have confidence in and trust their infrastructure maintenance or replacement mitigating strategies. One participant from a service delivery stakeholder in the chain commented as follows:

'So my view would be although infrastructure and rolling stock being a big part of that infrastructure it, it's my view that that has been fairly well mitigated from a risk point of view where we sit at this stage.' (Participant 6, white male, service provider, senior management).

It is important for TFR to acknowledge the risk of aged infrastructure and maintenance thereof. A risk of disruption in ageing infrastructure will be reduced through aggressive preventative maintenance programmes by all stakeholders in the chain, but particularly TFR owing to its strategic position in the logistics chain. This will not only reduce the risk of the occurrence of disruptions in the logistics chain but also reduce the impact of the loss. According to Transnet's LongTerm Planning Framework, (Transnet 2017a) Transnet made provision for the maintenance of fixed infrastructure and rolling stock.

\section{Technology}

Infrastructure technology is another risk category that could be identified from the interviews. Five of the eight participants reflected on technology, but with two different viewpoints on risk. One viewpoint sees the risk in not investing in the newest technology because of the efficiencies attached to new technology; and the other sees the risk in the adaptability of existing systems to new technology - therefore a risk if new technology is implemented. Two participants verbalised the technology dilemma as follows:

'So now is the time that they should be investing in latest technology and making assets, making the system as efficient as possible, which may mean that ultimately that you don't need expansionary capital, but you need sustaining capital and you obviously need maintenance. ... other heavy haul systems around the world, everything is moving to a far more automated environment, with technology being the underpin ... with seriously significant intelligence in this technology.' (Participant 1 , white male, consultant, all nodes)

'It is typically your new technology, where if the technology is here and that strategy work and we invested money and we bought these locos, now they are here, but where we haven't done enough homework from an operational perspective.'
(Participant 8, white female, large service provider, senior management)

From the above viewpoints, a conclusion could be arrived at that technology is seen to be a risk management tool on a strategic and tactical level. However, on an operational level, technology was identified as a risk that should be avoided. The main risk in technology is embedded in the approach to implementation and that approach determines whether technology is a risk, or a risk-mitigating category.

\section{Overvaal tunnel}

The Overvaal tunnel (TFR infrastructure) in Mpumalanga is a $1.4 \mathrm{~km}$ single-rail-line tunnel, built in the 1970s, linking the coal mines in Mpumalanga to the port of Richards Bay. It was already in the previous decade regarded as 'the biggest single bottleneck on the coal line' (Brown 2008). In this study, the Overvaal tunnel was recorded as a risk category by five of the eight participants:

Look, it's a known fact that one of the risks that we have on the coal line is to offload after the tunnel, you know? That seems to be the bottom line of our operation and obviously it impacts, you know, the coal exporter, TFR, RBCT, so definitely you know ...' (Participant 2, Indian male, large CEP, senior management)

So our timing with regards to increasing the export and moving GFB [general freight business] should be spot on, otherwise we are going to sit with a capacity issue at the Overvaal tunnel.' (Participant 8, white female, large service provider, senior management)

The issue is still in terms of risk that if there is more coal, in other words 91 million tons, how are we going to get that through the Overvaal tunnel?' (Participant 5, white female, large CEP, senior management)

Triangulation with the risk management policies and procedures of the stakeholders showed that the service provider stakeholders (Transnet Freight Rail and Richards Bay Coal Terminal) have focussed risk management policies and strategies to mitigate logistics infrastructure risk, while the CEPs have only a more general focus on infrastructure risk mitigation, most probably because they do not regard logistics as part of their core business of mining.

The most applicable mitigation strategy will be risk elimination through investment in doubling the tunnel. According to Transnet's 2016 financial statements, R2.7bn had been earmarked to expand capacity on this export coal line to 81 million tonnes per annum. At the Overvaal tunnel, a new double-track tunnel was planned to be constructed adjacent to the existing tunnel. In all, R3.5bn had been approved for the doubling of the Overvaal tunnel. However, execution had not commenced owing to further assessments being conducted for an alternative technology solution to develop the tunnel (Transnet 2016). According to Transnet's Long-Term Planning Framework (Transnet 2017b:89), they plan to complete the doubling of the Overvaal tunnel by 2023, thereby increasing its capacity from 81 million ton per annum to 110 million ton per annum. 
In conclusion to Theme 1 - Infrastructure: If the risk matrix in Figure 1 is applied, the risk scoring for infrastructure is as follows: Likelihood of risk occurring $=4$ and Severity of risk $=4$. From this it is deduced that this is a very high risk item $($ risk score $=16)$.

\section{Theme two - Macro-economy}

In the 'Background' section above it was mentioned that coal is a strategic, but declining, foreign currency earner in the South African economy. All the participants in this study viewed the macro-economy of coal as a risk factor. The macro-economy includes issues such as economic conditions, commodity prices, market trends and the future of coal. The negative views on coal and its impact on the environment have resulted in a precipitous decline in the use of coal by the major economies of the world. There has been a total shift from European markets to Asia, and India accounts for almost half of South Africa's coal export volumes - a trend expected to continue in the foreseeable future (CMSA 2018).

The macro-economy influences the willingness of the stakeholders in the bulk coal chain to invest in infrastructure. Two participants viewed the risk as follows:

'There's one primary risk that dominates now, and that's to do with the future of the coal industry, and the assessment of the service providers, in this case the TFR, around the future of the industry and their level of investment or commitment. So what you find is that at the moment, and this is the second or third cycle that they've been through, where there's been a lack of investment because of the view that they've taken on the market and the players in the market.' (Participant 1, white male, consultant, all nodes)

'... now in a, in an economic and commodity downturn, that we are seeing now, that's a major risk.' (Participant 5, white female, large CEP, senior management)

The country's macro-economic conditions also pose risks of another nature:

'Theft and vandalism is obviously a result of the economy; you know the root cause is unemployment as a result obviously of various issues.' (Participant 7, mixed race male, large service provider, senior manager)

From a triangulation viewpoint, the findings from the content analysis of CEPs' policies and procedures revealed the macroeconomy as a risk. Richards Bay Coal Terminal and TFR also reported the macro-economy of coal as a market risk in their policies and procedures. The data further revealed that this macro-economic risk may be the root cause and origin of other risks such as infrastructure, operational and people risks.

The research data suggested the macro-economic risk can be reduced by long-term agreements with international customers to stabilise revenue and investment in infrastructure. A participant explained it as follows:

'Okay, I would still say long-term agreements to create stability and to mitigate the risk involved in the fluctuating commodity price as well as the fluctuating exchange rates; but also it creates a sense of stability in the mines where they know for a set period they have a dedicated customer that is bound to accept their product. So it makes things easier for them in terms of long-term plans, in terms of capital investments.' (Participant 7, mixed race male, large service provider, senior manager)

In conclusion to Theme 2 - Macro-economy: If the risk matrix in Figure 1 is applied, the risk scoring for macro-economy is as follows: Likelihood of risk occurring $=4$ and Severity of risk $=4$. From this it is deduced that macro-economy is a very high risk item (risk score $=16$ ).

\section{Theme three - Uncontrollable events of nature}

It emerged from the data that five participants shared a concern about uncontrollable events of nature. Weather and weather conditions, as such, are an external risk factor that should be considered and managed (Schmidt \& Raman 2012:10). South Africa is a water-scarce country. Water is of particular importance for the bulk coal export chain. Without water, coal cannot be washed or processed. Water as a derivative of uncontrollable events of nature and weather patterns poses a risk to the coal mining industry in terms of its production. Should the mines not be able to process and provide coal for export, then the derived need for logistics is at risk. No wonder droughts and the availability of water was a major concern for the participants of the study. One participant verbalised his or her concern as follows:

'... in the next 5,10 years it could be challenging because weather patterns we identified as a risk, and our - I mean here, and the world, is just like heating up and you know, the drought.' (Participant 2, Indian male, large CEP, senior management)

Individual stakeholders indicated that they are reducing this risk through internal risk-mitigating strategies such as the reuse of water and mine reservoirs.

In conclusion to Theme 3 - Uncontrollable events of nature: If the risk matrix in Figure 1 is applied, the risk scoring for uncontrollable events of nature is as follows: Likelihood of risk occurring $=3$ and Severity of risk $=3$. From this it is deduced that this is a medium risk item (risk score $=9$ ).

\section{Theme four - Operations and management in the chain}

Operational and management level risks were identified by multiple participants. There is an overlap of, or interrelationship between, the operational level and management level risk theme and other themes. This was revealed by this study and confirms Mandal's (2011) point that demand, supply and cost factors are not only strategic but also inherently operational risks in the logistics chain.

\section{Management level risk}

A management level risk in the logistics chain that was identified is the lack of an aligned vision (objectives and goals) and communication among stakeholders in the chain. Half of the participants highlighted this risk. One participant viewed it as follows:

'Um so you know, looking at it from an integrated point of view and the risks, I do think one of the biggest risks that we face in 
this industry is misalignment of ultimate objectives.' (Participant 6 , white male, service provider, senior management)

Six of the eight participants reported a lack of communication as a source of risk. Some verbalised it as follows:

'If I summarise that, the long-term planning and communication poses a risk as the preparation and planning for infrastructure might not be aligned.' (Participant 8 , white female, large service provider, senior management)

'So if I can summarise that, information communication flow can be improved between those parties. Exactly, and that will prompt quick decisions-critical decisions.' (Participant 8, white female, large service provider, senior management)

'And also if there is, if there is communication or the sharing of the information, it also provokes someone else then to say that risk might be a risk to myself as well, let me go and check how exposed I am.' (Participant 4, black male, service provider, senior management)

The risk of a lack of aligned vision and communication can be eliminated or reduced in the supply chain and within stakeholders by cooperative planning and formal and nonformal communication channels.

\section{Electricity supply and operational level issues}

Operational risk includes electricity supply and other issues on an operational level that may occur, such as the breakdown of a piece of equipment.

Electricity was identified as a risk by five of the eight participants, four of whom were from the service supplier grouping (TFR and RBCT).Some participants explained the electricity problems as follows:

'You know we, you look at ... [participating stakeholder] and we have always, we have dual lines that are supplying us with electricity. We had an instant where both lines failed within twenty hours of each other.' (Participant 4, black male, service provider, senior management)

'You know we have started engagements with Eskom, if you remember two years ago Eskom was one of our high risks.' (Participant 7, mixed race male, large service provider, senior manager)

'Because we all seem to depend on Eskom, and you know with the growth and so on, the last years have been seriously hampered because of the lack of electricity.' (Participant 2, Indian male, large CEP, senior management)

Operational risks are also interrelated with other issues and can appear as symptoms in other themes and categories. For example, operational risks can occur as a result of labour and social impact. All stakeholders in the bulk coal export chain are subject to these risks. Part of operational management is to manage the day-to-day risk.

In the process of triangulation, the content analysis of the policies and procedures of the participants' companies revealed that the risks are managed on an operational and management level (on a tactical and strategic level). On an operational level, the policy and procedures enforce the management of risks and this is evident in the risk management systems, reports, committees and scheduled meetings. The risk management processes of the stakeholders were in each instance focussed on the specific company.

With regard to risk management (mitigation) on a management level, it was indicated that in a particular segment of the bulk coal export chain, risk management is actioned in a scheduled monthly meeting, where the operational processes are reviewed, the risks in the processes are identified, new risks are identified and mitigation actions for incidents that occurred during the review period are discussed. This was not done by all the stakeholders in this logistics chain.

In conclusion to Theme 4 - Operations and management risk in the chain: If the risk matrix in Figure 1 is applied, the risk scoring for operations and management is as follows: Likelihood of risk occurring $=2$ and Severity of risk $=4$. From this it is deduced that this is a medium risk item (risk score $=8$ ).

\section{Theme five - People as a risk}

'People' were identified as a risk by all the participants, in one way or another. From the data, the overarching findings were that people are the key and can be either a source of risk, or a risk absorber (Fuchs \& Wohinz 2009:234).

The theme of 'People' has two categories, namely: people skills, and labour and social impact.

\section{People skills}

The people skills risk was highlighted by two participants as follows:

'... you need to just make sure in your company that you've got the right skills employed to manage this part of your business with the necessary experience and networks.' (Participant 3, white male, small CEP, senior management)

'It is to have that expertise and knowledge to understand why it is so important to have a balanced system.' (Participant 8, white female, large service provider, senior management)

A lack of skills in logistics planning, management and execution can lead to disruption in the logistic chain (Fuchs \& Wohinz 2009:234). The lack of skilled people and losing skills in the bulk coal export chain pose a risk. This was verbalised as follows:

'Again, firstly if we look at ... [participating stakeholder's] major lack of skills...' (Participant 5, white female, large CEP, senior management)

'If I can look further, and you know I think in terms of ... [participating stakeholder], we talk about skills, ... we are losing in terms of brain drain.' (Participant 2, Indian male, large CEP, senior management)

'I think we are losing some expertise on the coal line.' (Participant 8 , white female, large service provider, senior management) 
In summary, the lack of skills and the exit of skilled people, in the absence of a succession planning programme, pose a significant risk. The content analysis confirms this and most of the participants view current skills, knowledge or expertise in the bulk coal export chain to be a risk. The CEPs were particularly vocal about this. Participants indicated that succession planning and knowledge transfer is the way to mitigate this risk. One participant's view is:

'... to have your succession plan to such an extent that smooth transitions between the retiree and the young taking over.' (Participant 3, white male, small CEP, senior management)

\section{Labour and social impact}

Wagner and Bode (2008:311) identify sabotage, vandalism, labour strikes and industrial incidents as human-centred issues that cause risk. The findings of this study confirm that 'labour and social impact' is a risk. This risk also manifested as a symptom in other themes and categories. Different participants' views on labour and social impact risk are as follows:

'And again labour, and those are challenges in any one of the three, whether it's at the mine, whether it's at TFR, whether it's at the terminal.' (Participant 1, white male, consultant, all nodes)

'I know this is political, a political slant, but I think our country's biggest risk doesn't matter what you analyse, is that people not having stuff, starting to become more and more demanding, want their fair share of the cake.' (Participant 3, white male, small CEP, senior management)

'Because they've got nothing to lose, so you will start having labour unrest, ... influencing the normal execution of business.' (Participant 3, white male, small CEP, senior management)

'There's the likelihood of having strikes ... we have a culture in South Africa.' (Participant 2, Indian male, large CEP, senior management)

The labour disputes and labour unrest actually go further than just the employees of the stakeholders in the coal chain. It includes the socio-economic circumstances of communities which are often used by politicians for furthering their own agenda. These risks are thus complex and require attention and innovative ways to mitigate them.

In the policies and procedures of the participating companies, the code 'people' in the theme relates to employees. It was further established that the code 'people' also includes the intent to protect people and employees against risk. The intent to protect the business against strikes, labour unrest and community actions is embedded on both a strategic and tactical level. There are specific strategies in the risk management policies and procedures to manage community relationships.

The participants suggested various ways in which they try to mitigate the risk:

'I know the mining sector has a joint wage discussion, but I think we should look at long-term agreements as a way of mitigating the labour issues.' (Participant 7, mixed race male, large service provider, senior manager)

A proactive strategy can provide a risk-mitigating solution. As stated by by a participant:

'I think the community management; it is not a root cause, it's a result of our inability or lack of a strategy to proactively manage the communities across the line.' (Participant 7, mixed race male, large service provider, senior manager)

'They do add value, if I can use the community involvement as an example. All our initiatives are sponsoring primary schools, doing mobile libraries to the communities and we have seen that a lot of the communities, especially here in ... [place] where we have started to proactively engaged with, we find that the incidents of theft and the incidents of disruptions on the railway lines are significantly decreased.' (Participant 7, mixed race male, large service provider, senior manager)

'Labour and social impact' was identified to be a category of risk and possible mitigating actions could be longer-term wage agreements with labour and a proactive community strategy.

In conclusion to Theme 5 - People: If the risk matrix in Figure 1 is applied, the risk scoring for people is as follows: Likelihood of risk occurring $=3$ and Severity of risk $=5$. From this it is deduced that this is a high risk item (risk score $=15)$.

\section{Summary}

The risks identified by the participants in the bulk coal export logistics chain were: infrastructure, the macro-economy, uncontrollable events of nature, disruptions and risk that occur in operations and management, and people skills and labour and social impact. Of these risks, it was found that the most important ones were infrastructure, the macro-economy, and people risk. Table 3 summarises the risk scoring of the different risks identified and analysed in the bulk coal export logistics chain and the risk mitigation.

\section{Discussion and recommendations Infrastructure}

With regard to the infrastructure risk, there seems to be underlying tension between the CEPs and TFR. The CEPs consider investment in upgrading and maintaining rail transport as a big concern. The CEPs feel that TFR is not committed to investing capital in the expansion and upgrading of the Mpumalanga-Richards Bay coal link. The coal link is long and ageing and needs investment in maintenance and more advanced technology. They feel that TFR's priority is elsewhere, for example, in investing in rail infrastructure for bulk coal transport in the Limpopo Province. The Overvaal tunnel has been a serious problem for an extended time and the perception exists that TFR is 'dragging its feet' on this matter. From the findings, TFR seems not as much concerned with the rail transport system. It is recommended that the CEPs should try to convince 
TABLE 3: Summary of risk scores and mitigation.

\begin{tabular}{lccl}
\hline Risk item & Risk score & Risk mitigation \\
\hline Infrastructure risk & 16 & $\begin{array}{l}\text { Focussed risk management policies and } \\
\text { strategies to mitigate logistics infrastructure risk }\end{array}$ \\
Macro-economy & 16 & $\begin{array}{l}\text { Long-term agreements with international } \\
\text { customers to stabilise revenue and investment in } \\
\text { infrastructure }\end{array}$ \\
$\begin{array}{l}\text { Uncontrollable events } \\
\text { of nature }\end{array}$ & 9 & $\begin{array}{l}\text { Internal risk-mitigating strategies such as the } \\
\text { re-use of water and mine reservoirs }\end{array}$ \\
$\begin{array}{l}\text { Operations and } \\
\text { management risks }\end{array}$ & 8 & $\begin{array}{l}\text { Risk management is actioned in a scheduled } \\
\text { monthly meeting, where the operational } \\
\text { processes are reviewed, the risks in the } \\
\text { processes are identified, new risks are identified } \\
\text { and mitigation actions for incidents that occurred } \\
\text { during the review period are discussed }\end{array}$ \\
People as a risk & 15 & $\begin{array}{l}\text { Longer-term wage agreements with labour and a } \\
\text { proactive community strategy }\end{array}$ \\
\hline
\end{tabular}

TFR to recognise the importance of this line with an expansion of long-term export delivery contracts. Then TFR needs to invest in making the coal line more efficient and reliable for CEPs and RBCT, to ensure the capacity to handle a growth in export. It is of the utmost importance that TFR should be more open to the other stakeholders about their intentions with the coal line, to eradicate uncertainty among the other stakeholders. Better communication between the parties with regard to planning in terms of infrastructure and technology might relieve the tension between the stakeholders.

\section{Macro-economic risks}

As indicated before, macro-economic risks include issues such as economic conditions, commodity prices, market trends and the future of coal. All the stakeholders are in agreement that the macro-economy is one of the most important risks they face. It influences the willingness of all the stakeholders in the bulk coal export logistics chain to invest in infrastructure, but particularly the service providers in the logistics chain. It was found that the macro-economic risk is the root cause and origin of other risks such as infrastructure, and operational and people risks.

The research data suggest that there should be long-term agreements in place to stabilise demand, prices and the willingness to invest in infrastructure. The macro-economy, particularly supply and demand, and hence the price of the commodity, is a risk for the chain as a whole, and it makes sense for the stakeholders to cooperatively strategise around this risk, which also contributes to the other risks identified in the study.

\section{Uncontrollable events of nature}

Five participants shared their concern about droughts and the scarcity of water in the country. Water is of particular importance for the bulk coal export chain. Without water, coal cannot be washed or processed. Should the mines not be able to process and provide coal for export, then the derived need for logistics is at risk. Individual stakeholders indicated that they are mitigating this risk through internal riskmitigating strategies such as the re-use of water and mine reservoirs.

\section{Operational and management risk}

Two important management risk elements that were identified are a lack of (1) communication and (2) an aligned vision among the stakeholders in the logistics chain.

Electricity supply is a common risk that all the stakeholders are subject to. With regard to operational risk, most of the stakeholders in the chain regard skills in, and knowledge of, engineering, maintenance and equipment, and the expertise of operational level employees as a risk. Also, all the stakeholders are subject to the risk of labour and social unrest. For the risks experienced by all the stakeholders, it is suggested that stakeholders work together, for example, by sharing experiences and intelligence, fostering sensitivity in the chain and brainstorming to mitigate these risks which may affect the whole chain.

\section{People as a risk}

People risk in South African coal logistics refers particularly to the lack of skilled people and labour relations. From the findings, it became clear that the bulk coal export chain is losing skilled people. The lack of skills and the exit of skilled people, in the absence of succession planning programmes, pose a significant risk.

The findings of this study confirm that 'labour disputes and unrest' are a real risk. This risk manifested as a symptom in other risk categories as well, because it actually goes further than just the employees of the stakeholders in the coal chain. It includes the socio-economic circumstances of communities and thus requires attention and innovative ways to mitigate it. Possible mitigating actions can be longer-term wage agreements with labour and a proactive community strategy.

It is clear from the findings and discussions that there are some risks that are unique to each particular stakeholder. It could be confirmed (from interviews and the content analysis of documents) that most of the stakeholders have mitigation strategies in place.

There are, however, many risks that are experienced by all of the stakeholders in the logistics chain, such as infrastructure, and macro-economic, operational and management and people risks. It would make sense for them to cooperatively strategise to mitigate these risks. Unfortunately, this is not practised in the bulk coal export chain. It was found that there is a lack of communication and an aligned vision (objectives and goals) among stakeholders in the chain, and this manifested in underlying tension between the parties. Some of the participants also suggested a cooperative strategy, particularly for managing infrastructure risks:

'And it cannot, it's not sustainable in the way that it's sitting right now. You need to change the whole landscape and people need to open their minds and literally welcome the support and the input from the other places and recognise that there are some 
best of breeds, and best of expertise in each one of the parties. And by doing that you'll find you'll be able to reduce, significantly I believe, on the expansionary capital, or you know, effectively manage it.' (Participant 1, white male, consultant, all nodes)

'It is capital, but it is all about how well you move a product, say from a new mine. I think there is a lack of cooperation in the industry to consolidate infrastructure and I think it's the only way that we will see the coal industry being able to move forward if there is some consolidation because at the moment it is so hard to consolidate anything and that to me poses a great risk.' (Participant 4, black, male, service provider, senior management)

It can therefore be suggested that the stakeholders in the bulk coal export logistics chain manage their risks in two ways: (1) Each company should make provision for managing its specific risks with an internal strategy, or do so in cooperation with other similar stakeholders (e.g. CEPs) in the logistics chain and (2) stakeholders should strategise with all the other stakeholders in the chain about the risks they all experience in an integrated manner. It is an accepted idea in supply chain management theory and practice that working closely together in a supply chain leads to innovativeness and an improvement of efficiencies and effectiveness in the chain, the effect of which is much greater than the sum of the individual efforts.

Despite the existence of the Channel Oversight Team (COT) of the bulk coal export logistics chain (who aim to 'cooperatively seek to ensure international competitiveness of the coal logistics chain and to focus on extracting efficiency and productivity opportunities in the channel'), there is little evidence that this team has brought about close cooperation and trust between the stakeholders. The suggestion is therefore made that this team revisit its mandate and forge closer customer and supplier relationships, to such an extent that they can plan and strategise together to mitigate risks that influence the whole logistics chain. It should be recognised that all the stakeholders in the chain is of equal importance for the sustainability of the chain.

\section{Conclusion}

The study specifically focussed on a stakeholder view of the risks experienced in the bulk coal export logistics chain. However, TFR is a state-owned enterprise (SOE) which operates throughout South Africa and the bulk coal export chain is not as important for them as for the other stakeholders in this chain. Being a SOE, TFR is obliged to follow the priorities of the state or government of the day. It is therefore impossible to strategise without taking government priorities into account, or to strategise without the inputs of high-level government.

It is suggested in this study that the importance of the bulk coal export logistics chain for the country as whole be decided on the highest level, and that resources be made available and priorities be determined accordingly. This suggestion is in line with the Coal Strategy of the Chamber of Mines/Minerals
Council South Africa (CMSA 2018), where they foresee to (1) expand export infrastructure and (2) explore potential bilateral trade agreements with potential export markets. This will only be possible through cooperation between Transnet (TRF), the National Treasury, the Department of Trade and Industry and the Department of International Relations and Cooperation (CMSA 2018).

Exports are essential in bringing into the country the foreign exchange which South Africa needs to import, among other things, raw materials and foreign technology, and also to service public and private external debt (CMSA 2018). Therefore, a renewed focus on the role of the bulk coal export logistics chain and its contribution in this regard is needed.

This research was limited to the bulk coal export logistics chain in South Africa. Although every effort was made with the application of the research methodology to ensure trustworthiness of the data, the claim cannot be made that the findings are representative of all bulk commodity export chains. The value of the study is seated in the theoretical perspective of the study and the suggested recommendations, which may be applied to other bulk commodity export chains in South Africa and bulk commodity export chains in other developing countries.

\section{Acknowledgements}

The authors thank the participants of this study for their willingness to participate and for their valuable inputs.

\section{Competing interests}

The authors declare that they have no financial or personal relationships that may have inappropriately influenced them in writing this article.

\section{Authors' contributions}

The article is based on the M.Com dissertation of A.B., with J.A.B-W. as the supervisor. Both authors contributed equally in the conceptualisation, writing and preparation of the article.

\section{Disclaimer}

The views expressed in this article are that of the researchers and not an official position of the institutions.

\section{References}

Bandaly, D., Satir, A., Kahyaoglu, Y. \& Shanker, L., 2012, 'Supply chain risk management-l: Conceptualization, framework and planning process', Risk Management 14(4), 249-271. https://doi.org/10.1057/rm.2012.7

Benyahia, S., 2012, 'A comparative study of the resilience of coal logistics chains in Australia, South Africa and Canada', viewed 16 April 2016, from https://papyrus. bib.umontreal.ca/xmlui/bitstream/handle/1866/8680/Benyahia_Sefiane_2012_ memoire.pdf?sequence $=6$.

Bereriche, Y. \& Ait-Kadi, D., 2015, 'Contingency design for reliability in a supply chain', International Journal of Risk and Contingency Management 4(2), 31-44. https:// doi.org/10.4018/IJRCM.2015040103 
Boland, N. \& Savelsbergh, M., 2012, 'Optimizing the Hunter Valley Coal Chain', in H. Gurnani, A. Mehrotra \& S. Ray (eds.), Supply chain disruptions: Theory and practice of managing risk, pp. 275-302, Springer, London.
prantion

Borge, D., 2001, The book of risk, 1st edn., Wiley, New York.

Bowersox, D., Closs, D., Cooper, M. \& Bowersox, J., 2013, Supply chain logistic management, 4th edn., McGraw-Hill, New York.

Breakwell, G., 2014, The psychology of risk, 2nd edn., Cambridge University Press, Cambridge.

Breuer, C., Siestrup, G., Haasis, H. \& Wildebrand, H., 2013, 'Collaborative risk management in sensitive logistics nodes', Team Performance Management 19(7/8), 331-351. https://doi.org/10.1108/TPM-11-2012-0036

Botha, T., Badenhorst-Weiss, J.A., Bimha, A., Chodukufa, K., Cohen, T. Cronje, L. et al., 2016, Corporate citizenship, Oxford University Press, Cape Town.

Brown, J., 2008, 'Tunnel may cost Transnet R11bn', Economy, viewed 15 May 2018 from https://www.iol.co.za/business-report/economy/tunnel-may-cost-transnetr11bn-715064

Christopher, M. \& Lee, H., 2004, 'Mitigating supply chain risk trough improved confidence', International Journal of Physical Distribution and Logistics Management 34(5), 388-396. https://doi.org/10.1108/09600030410545436

Christopher, M., Mena, C., Khan, O. \& Yurt, O., 2011, 'Approaches to managing global sourcing risk', Supply Chain Management: An International Journal 16(2), 67-81. https://doi.org/10.1108/13598541111115338

CMSA, 2018, Coal strategy 2018, Chamber of Mines South Africa, viewed 05 September 2018, from www.mineralscouncil.org.za/component/jdownloads/ send/25.../535-coal-strategy-2018

Creswell, J., 2013a, Research design: Qualitative, quantitative, and mixed methods approaches, 4th ed., Sage, Thousand Oaks, CA.

Creswell, J., 2013b, Qualitative inquiry and research designs - Choosing amongst five approaches, 3rd edn., Sage, Thousand Oaks, CA.

Creswell, J.W., 2009, Research design: Qualitative, quantitative and mixed methods approaches, Sage, Thousand Oaks, CA.

Elahi, E., 2013, 'Risk management: The next source of competitive advantage', Foresight 15(2), 117-131. https://doi.org/10.1108/14636681311321121

Elo, S., Kääriäinen, M., Kanste, O., Pölkki, T., Utriainen, K. \& Kyngäs, H., 2014, 'Qualitative content analysis - A focus on trustworthiness', Sage Open 4(1), 1-10. 'Qualitative content analysis - A focus on trustwo
https://doi.org/10.1177/2158244014522633

Eriksson, P. \& Kovalainen, A., 2008, Qualitative methods in business research, Sage, Thousand Oaks, CA.

Ernst, A., Krishnamoorthy, M., Sier, D. \& Marquez, L., 2008, 'Solving regional infrastructure bottlenecks: Rail allocation policies for a coal terminal', Australasian Journal of Regional Studies 14(2), 177-193.

Fawcett, S., Waller, M. \& Bowersox, D., 2011, 'Cinderella in the C-suite: Conducting influential research to advance the logistics and supply chain disciplines', Journal of Business Logistics 32(2), 115-121. https://doi.org/10.1111/j.2158-1592.2011. 01010.x

Fuchs, H. \& Wohinz, J., 2009, 'Risk management in logistic systems', Advances in Production Engineering and Management 4(4), 233-242.

Gammelgaard, B. \& Flint, D., 2012, 'Qualitative research in logistics and supply chain management: Beyond the justification for using qualitative methods', International management: Beyond the justification for using qualitative methods', International
Journal of Physical Distribution and Logistics Management 42(8/9), 721-725. Journal of Physical Distribution and Logistics Manage
https://doi.org/10.1108/ijpdlm.2012.00542haa.001

Gurning, S. \& Cahoon, S., 2009, Analysis of random disruptive events in shipping and port operations, Australian Maritime College, Hong Kong.

Hallberg, L., 2010, 'Some thoughts about the literature review in grounded theory studies', International Journal of Qualitative Studies on Health and Well-Being 5(3), 5387. https://doi.org/10.3402/qhw.v5i3.5387

Hausman, W., Lee, H. \& Subramanian, U., 2013, 'The impact of logistics performance on trade', Productions and Operations Management 22(2), 236-252. https://doi. org/10.1111/j.1937-5956.2011.01312.x

Hirschinger, M., Hartman, E., Von der Gracht, H. \& Darko, L., 2015, 'The future of logistics in emerging markets', Journal of Supply Chain Management 51(4), 73-93. https://doi.org/10.1111/jscm.12074

Hopkin, P., 2012, Fundamentals of risk management - Understanding, evaluating and implementing effective risk management, 2 nd edn., Kogan Page Limited, London.

Hugo, W.M.J. \& Badenhorst-Weiss, J.A., 2011, Purchasing and supply management, 6th edn., Van Schaik, Pretoria.

Institute of Risk Management (IRM), n.d., Knowledge and resources: 'Risk appetite and tolerance', viewed 12 September 2018, from https://www.theirm.org/ knowledge-and-resources/thought-leadership/risk-appetite-and-tolerance.aspx.

Intelex Library, nd. Risk Matrix Example, viewed 9 January 2019, from https:// community.intelex.com/library/peer-resources/risk-matrix-example

Kern, D., Moser, R., Hartmann, E. \& Moder, M., 2012, 'Supply risk management: Model development and empirical analyses', International Journal of Physical Distribution and Logistics Management 42(1), 60-82. https://doi.org/10.1108/ 09600031211202472

Kessinger, C. \& Macmorrow, J., 2012, 'Supply chain risk management: A perspective from practice', in P. Kouvelis, L. Dong, O. Boyabatli \& R. Li (eds.), Handbook of integrated risk management in global supply chains, pp. 515-535, Wiley, New York.

Kumar, M. \& Gregory, M., 2013, 'An exploration of risk management in global industrial investment', Risk Management 15(4), 272-300. https://doi.org/10.1057/ $\mathrm{rm} .2013 .8$
Latif, B., Gohar, F., Hussain, A. \& Kashif, M., 2013, 'Barriers to effective strategic planning', International Journal of Management and Organizational Studies 1(2), plannin

Lockamy, A. III, 2014, 'Assessing disaster risks in supply chains', Industrial Management and Data Systems 114(5), 755-777. https://doi.org/10.1108/IMDS-11-2013-0477

Luger, K., 2008, 'Approaches to railway efficiency improvement', in Chinese railways: Contributions to economics, pp. 217-242, Physica-Verlag, Heidelberg, Germany.

Luhanga, P., 2017, 'Transnet looks to build two new heavy haul rail lines', fin24.com 10 September, viewed 10 September 2018, from https://www.fin24.com/ Companies/Industrial/transnet-looks-to-build-two-new-heavy-haul-raillines-20170908.

Mandal, S., 2011, 'Supply chain risk identification and elimination: A theoretical perspective', Journal of Supply Chain Management 8(1), 68-86.

Mathu, K. \& Chinomona, R., 2013, 'South African coal mining industry: Socioeconomic attributes', Mediterranean Journal of Social Sciences 4(14), 347-358 https://doi.org/10.5901/mjss.2013.v4n14p347

McLaughlin, B.D., 2015, 'Comprehensive risk abatement methodology as a lean operations strategy', International Journal of Risk and Contingency Management 4(1), 39-52. https://doi.org/10.4018/ijrcm.2015010103

Merriam, S., 2015, Qualitative research: A guide to design and implementation Revised and expanded from qualitative research and case study applications in education, 2nd edn., Wiley, San Francisco, CA.

Merriam-Webster, n.d., www.merriam-webster.com, viewed 09 January 2019, from http://www.merriam-webster.com/dictionary/resilience.

Mining Weekly, 2018, 'Transnet reject claim of no significant mining linked rail and port investment in 15 years', viewed 03 September 2018, from http://www. miningweekly.com/article/transnet-rejects-claim-of-no-significant-mining-linkedminingweekly.com/article/transnet-rejects-claim-of-

Olson, D. \& Dash Wu, D., 2010, 'A review of enterprise risk management in supply chain', Kybernetes 39(5), 694-706. https://doi.org/10.1108/03684921 011043198

Patton, M., 2015, Qualitative research and evaluation methods: Integrating theory and practice, 4th ed., Sage, Thousand Oaks, CA.

Peck, H., 2006, 'Reconciling supply chain vulnerability, risk and supply chain management', International Journal of Logistics Research and Applications 9(2), 127-142. https://doi.org/10.1080/13675560600673578

Roe, A. \& Haglund, D., 2012, The role of mining in national economies, International Council on Mining and Metals (ICMM), London.

Rose, A. \& Wei, D. 2013. 'Estimating the economic consequences of a port shutdown The special role of resilience', Economic Systems Research 25(2), 212-232.Ryan, B., 2014, 'South Africa coal industry muddling along', Financial Mail, 27 March, viewed 25 August 2014, from http://www.financialmail.co.za/coverstory/2014/03/27/ sa-s-coal-industry-muddling-along.

Saldaña, J., 2011, Fundamentals of qualitative research, Oxford University Press, New York.

Schmidt, W. \& Raman, A., 2012, When supply chain disruptions matter, Harvard Business School Working Paper No. 13-006, July 2012. (Revised January 2013. Harvard Business School, Boston, MA.

Seccombe, A., 2018, 'Why prospects for coal are looking up', Business LIVE, viewed 15 September 2018, from https://www.businesslive.co.za/bd/companies/ mining/2018-02-08-why-prospects-for-coal-are-looking-up/.

Shenton, A.K., 2004, 'Strategies for ensuring trustworthiness in qualitative research projects', Education for Information 22, 36-57. https://doi.org/10.3233/EFI-200422201

Simchi-Levy, D., Kaminsky, P. \& Simchi-Levy, E., 2009, Designing and managing the supply chain: Concepts, strategies and case studies, 3rd edn., McGraw-Hill, New York.

Sivhaga, A., 2012, Reduction of loading variability at Exxaro Coal operations, s.n., Pretoria.

Smit, C., 2013, 'The role of mining in the South African Economy', KPMG South Africa Blog, viewed 09 June 2014, from http://www.sablog.kpmg.co.za/2013/12/rolemining-south-african-economy/.

Smith, J. \& Firth, J., 2011, 'Qualitative data analysis: The framework approach', The International Journal of Research Methodology in Nursing and Health Care 18(2), 52-62. https://doi.org/10.7748/nr2011.01.18.2.52.c8284

Sodhi, M.S., Son, B. \& Tang, C.S., 2012, 'Researchers' perspectives on supply chain risk management', Production \& Operations Management 21, 1-13. https://doi. org/10.1111/j.1937-5956.2011.01251.x

Son, J. \& Orchard, R., 2013, 'Effectiveness of policies for mitigating supply disruptions', International Journal of Physical Distribution \& Logistics Management 43(8), 684-706. https://doi.org/10.1108/IJPDLM-04-2012-0109

Sousa, D., 2014, 'Validation in qualitative research: General aspects and specificities of the descriptive phenomenological method', Qualitative Research in Psychology 11(2), 211-227. https://doi.org/10.1080/14780887.2013.853855

Statistics South Africa (STATS SA), 2017, Mining: A brief history, Department of Statistics, Pretoria, viewed 06 September 2018, from http://www.statssa.gov. $\mathrm{za} / \mathrm{p}=9720$.

Stecke, K. \& Kumar, S., 2009, 'Sources of supply chain disruptions, factors that breed vulnerability, and mitigating strategies', Journal of Marketing Channels 16(3), 193-226. https://doi.org/10.1080/10466690902932551 
Tomlin, B. \& Wang, Y., 2011, 'Operational strategies for managing supply chain disruption risk', in P. Kouvelis, L. Dong, O. Boyabatli \& R. Li (eds.). The handbook of disruption risk', in P. Kouvelis, L. Dong, O. Boyabatli \& R. Li (eds.), The handbook of
integrated risk management in global supply chains, pp. 79-101, Wiley, New York.

Touboulic, A. \& Walker, H., 2015, 'Theories in sustainable supply chain management: A structured literature review', International Journal of Physical Distribution \& Logistics Management 45(1/2), 16-42. https://doi.org/10.1108/IJPDLM-05-2013-

Toyota, 2011, 'Japan quake, tsunami take heavy toll on Toyota', Forbes, viewed 20 March 2018, from https://www.forbes.com/sites/greatspeculations/2011/04/08/ japan-quake-tsunami-take-heavy-toll-on-toyota/

Toyota, 2016, 'Toyota, other major Japanese firms hit by quake damage, supply disruptions', Fortune, viewed 20 March 2018, from http://fortune.com/2016 /04/17/toyota-earthquake-disruptions/

Tranchard, S., 2018, The new ISO 31000 keeps risk management simple, International Organization for Standardization, viewed 09 January 2019, from https://www.iso. org/news/ref2263.html.

Transnet, 2013, 'Transnet integrated report 2013', viewed 20 September 2018, from https://www.transnet.net/InvestorRelations/AR/2013/Integrated\%20Report.pdf
Transnet, 2016, 'Audited condensed consolidated financial results for the year ended 31 March 2016', viewed 15 September 2018, from https://www.transnet.net/ InvestorRelations/AR2016/2016/group-financial-position.html

Transnet, 2017a, 'Long term planning framework', in Capital planning, viewed 10 January 2019, from https://www.transnet.net/BusinessWithUs/LTPF\%202017/ LTPF\%20Chapter\%208\%20Capital\%20Planning.pdf

Transnet, 2017b, 'Long term planning framework: Chapter 3 rail development plan' viewed 07 January 2019, from https://www.transnet.net/BusinessWithUs/ LTPF\%202018/3.\%20LTPF\%202017_Rail.pdf

Vaismoradi, M., Turunen, H. \& Bondas, T., 2013, 'Content analysis and thematic analysis: Implications for conducting a qualitative descriptive study', Nursing and Health Sciences 15, 398-405. https://doi.org/10.1111/nhs.12048

Wagner, M. \& Bode, C., 2008, 'An empirical examination of supply chain performance along several dimensions of risk', Journal of Business Logistics 29(1), 307-325. https://doi.org/10.1002/j.2158-1592.2008.tb00081.x

Yan-liang, W., 2013, 'Research on the logistics supply chain in port logistics transportation', Research Journal of Applied Science, Engineering and Technology 6(20), 3715-3722. https://doi.org/10.19026/rjaset.6.3581 